\title{
Behavior of Reinforced Concrete Columns under
}

\section{Combined Axial Load and Bending in Accordance with a Nonlinear Numerical Model}

\author{
Carlos Eduardo Luna de Melo ${ }^{1}$ and Guilherme Sales Soares de Azevedo Melo ${ }^{2}$ \\ 1. Department of Technology, Faculty of Architecture and Urbanism, University of Brasilia, Brasilia 70910-900, Brazil \\ 2. Department of Civil Engineering and Environmental, Faculty of Technology, University of Brasília, Brasilia 70910-900, Brazil
}

\begin{abstract}
A nonlinear numerical model was developed to analyze reinforced concrete columns under combined axial load and bending up to failure. Results of reinforced concrete columns under eccentric compression tested to failure are presented and compared to results from a numerical nonlinear model. The tests involved 10 columns with cross-section of $250 \mathrm{~mm} \times 120 \mathrm{~mm}$, geometrical reinforcement ratio of $1.57 \%$ and concrete with compression strength around $40 \mathrm{MPa}$, with $3,000 \mathrm{~mm}$ in length. The main variable was the load eccentricity in the direction of the smaller dimension of cross-section. Experimental results of ultimate load and of the evolution of transverse displacements and concrete strains are compared with the numerical results. The estimated results obtained by the numerical model are close to the experimental ones, being suitable for use in verification of elements under combined axial load and bending.
\end{abstract}

Key words: Columns, reinforced concrete, combined axial load and bending, numerical analysis.

\section{Introduction}

Reinforced concrete columns are important structural elements, which, in a standard structure of building, have main function of supporting horizontal and vertical loads, transmitting these loads to foundations.

With the advent of the computers and high performance concretes, concrete structures became slenderer, with better use of concrete and reinforcement strength. Among the consequences of that technological advance, there is great likeliness to reach a limit state of instability of the columns.

The complexity of study of reinforced concrete elements under axial load and bending is due to its nonlinear behavior. The physical nonlinearity due to reinforced concrete and reinforcement constitutive nonlinear equations, the geometrical nonlinearity due

Corresponding author: Carlos Eduardo Luna de Melo, Ph.D., professor, research fields: structural engineering, numerical and experimental tests, reinforced and prestressed concrete structures. to iteration between internal forces and displacements due to load, lead to simplified or iterative solutions.

Knowing the behavior of columns under combined axial load and bending during loads steps until failure is very important, mainly in slender columns, where the second order effects are significant. Experimental studies are difficult to be done, and it is necessary to resort a cross section reduction of the column in order to avoid costs with frame tests and equipment, and consequently becoming a medium proportion test.

Having a numerical model to analyze reinforced concrete columns under combined axial load and bending is important to predict, to analyze test results and to design columns.

A nonlinear numerical model was developed based on work presented by Nagato [1], which considers compression field theory given by Vecchio and Collins [2]. The developed numerical model, called "FLECO2C", considers physical and geometrical nonlinearities. 


\section{Experimental Program}

Ten reinforced concrete columns with $250 \mathrm{~mm} \times 120 \mathrm{~mm}$ in cross section (area of cross section $A_{c}$ equals to $300 \mathrm{~cm}^{2}$ ) and concrete compression strength around $40 \mathrm{MPa}$ with 3,000 mm in length were tested.

The longitudinal reinforcement consisted of six 10-mm diameter bars (where $A_{s}$ is the area of six bars). The longitudinal steel ratio $\rho_{s}$ is equal to 1.57 and the slenderness $\lambda$ is equal to 90.9. The transversal reinforcement consisted of $5-\mathrm{mm}$ diameter rectangle stirrups, with $5 \mathrm{~mm}$ of diameter and $100 \mathrm{~mm}$ of spacing. Near to column ends the stirrups were $50 \mathrm{~mm}$ spaced. All these data were based on Refs. [3-6].
Geometry details of columns ends were used to measure rotations of columns ends and provide application of the eccentric load.

The main variable of tests was load eccentricity. Fig. 1 shows the columns sizes used in present work in $\mathrm{mm}$.

The columns were identified by the following notation: $P F N$ e- $L$, where, $P F N=$ column under axial load and bending, $e=$ load eccentricity in direction of less dimension of cross section $(\mathrm{mm})$ and $L=$ column length (m). Table 1 shows a summary of characteristics of columns. Further details about test data can be found in Refs. [3, 4, 7].

Each longitudinal bar and concrete compressed
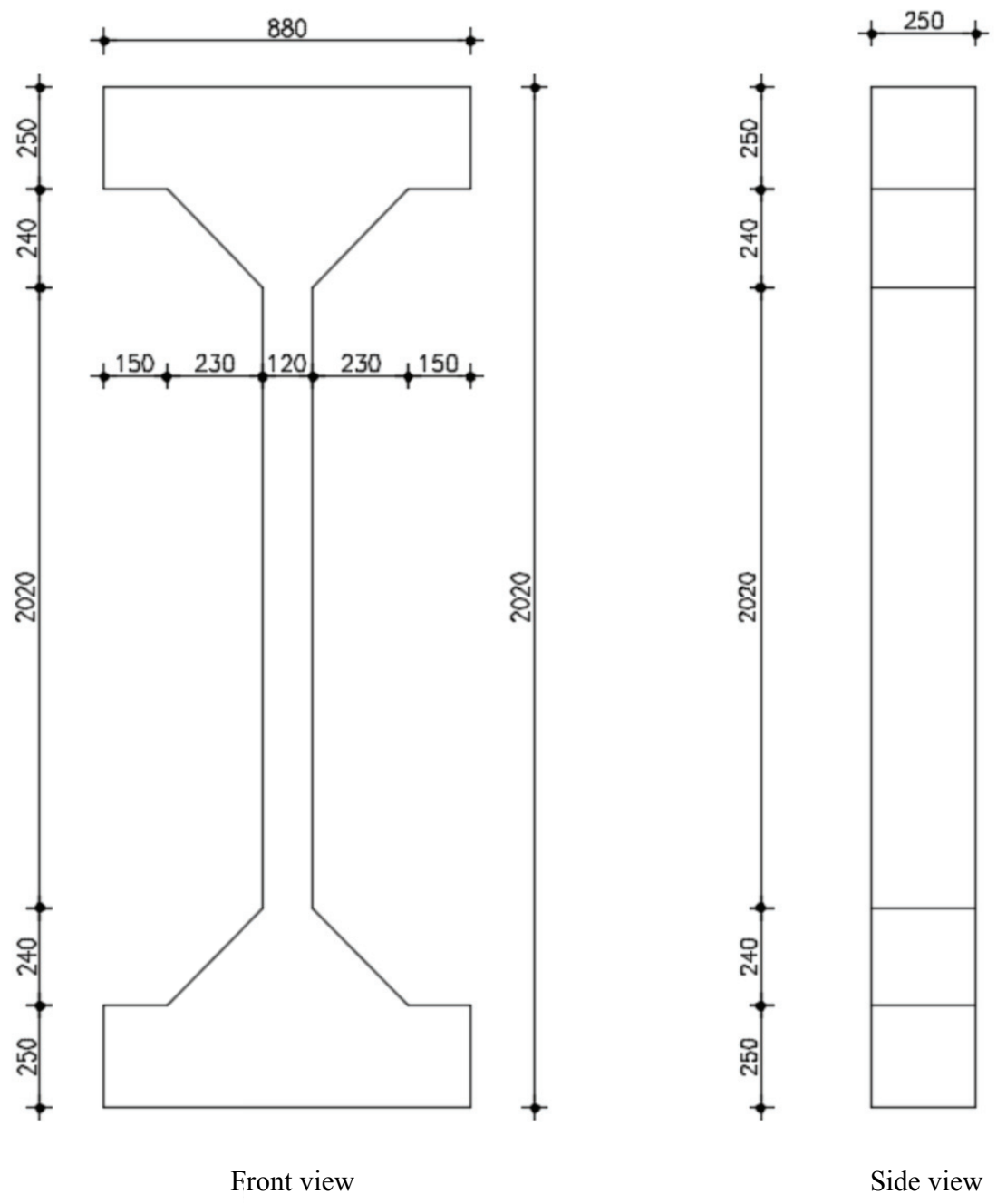

Fig. 1 Geometry details of concrete columns (units in mm). 
Table 1 Data for tested columns.

\begin{tabular}{|c|c|c|c|c|c|c|}
\hline Column & $e(\mathrm{~mm})$ & $\lambda^{*}$ & $L(\mathrm{~mm})$ & $A_{c}\left(\mathrm{~cm}^{2}\right)$ & $A_{s}\left(\mathrm{~cm}^{2}\right)$ & $\rho_{s}(\%)$ \\
\hline$P F N$ 0-3 & 0 & \multirow{10}{*}{90.9} & \multirow{10}{*}{3,000} & \multirow{10}{*}{300} & \multirow{10}{*}{4.71} & \multirow{10}{*}{1.57} \\
\hline PFN 6-3 & 6 & & & & & \\
\hline$P F N$ 12-3 & 12 & & & & & \\
\hline$P F N$ 15-3 & 15 & & & & & \\
\hline PFN 18-3 & 18 & & & & & \\
\hline PFN 24-3 & 24 & & & & & \\
\hline$P F N$ 30-3 & 30 & & & & & \\
\hline$P F N$ 40-3 & 40 & & & & & \\
\hline$P F N$ 50-3 & 50 & & & & & \\
\hline$P F N$ 60-3 & 60 & & & & & \\
\hline
\end{tabular}

${ }^{*}$ Considered 3,140 mm between pins.

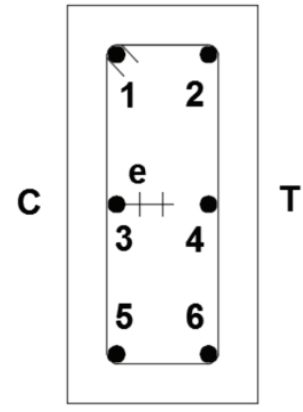

(a)

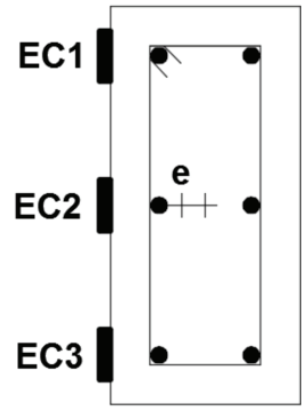

(b)
Fig. 2 Placement of strain gauges on: (a) reinforcement; (b) concrete surface.

surface were monitored at mid-height using strain gauges. The compressed surface is called C-face and the least compressed surface (or tensioned face) is called T-face. Fig. 2 shows the placement of strain gauges on reinforcement and concrete surface at middle height.

The columns were tested using a steel reaction frame, where the load was applied using a jack until column failure and measured using a load cell. The load eccentricity was applied moving the center of the plates from each column axe. Fig. 3 shows the test setup used with positioning of load cell, jack, rollers, column and electric deflections gauges (D1 to D7).

\section{Materials Tests}

Concrete compression strength was obtained by compression test, and tensile strength was obtained from the indirect tensile test (Brazilian test). The elastic modulus was obtained by tests of specimens, and in some cases, recommendations by Ref. [8] were used. Reinforcement strength was obtained by pull-out test. The concrete cylinder strength varied from 33.9 $\mathrm{MPa}$ to $39.7 \mathrm{MPa}$. Table 2 shows experimental results of concrete and steel.

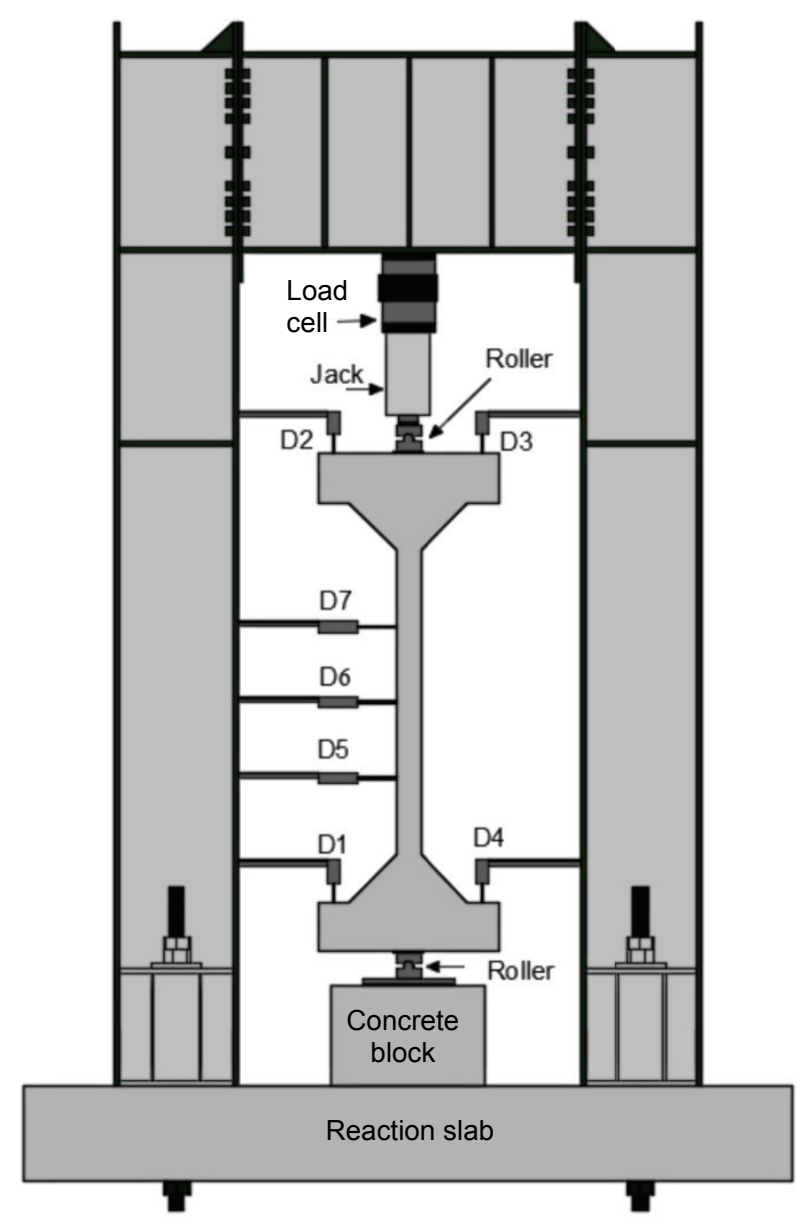

Fig. 3 Test setup for reinforced concrete columns under compression. 
Table 2 Experimental results of concrete and steel.

\begin{tabular}{|c|c|c|c|c|c|c|}
\hline Column & $f_{c}(\mathrm{MPa})$ & $f_{c t}(\mathrm{MPa})$ & $E_{c}(\mathrm{GPa})$ & $f_{y}^{*}(\mathrm{MPa})$ & $f_{u}^{*}(\mathrm{MPa})$ & $E_{s}{ }^{*}(\mathrm{GPa})$ \\
\hline PFN 0-3 & 35.8 & 3.1 & 28.7 & \multirow{10}{*}{595} & \multirow{10}{*}{705} & \multirow{10}{*}{190} \\
\hline PFN 6-3 & 39.6 & 2.5 & 32.1 & & & \\
\hline$P F N$ 12-3 & 39.6 & 2.5 & 32.1 & & & \\
\hline$P F N$ 15-3 & 35.8 & 3.1 & 28.7 & & & \\
\hline$P F N$ 18-3 & 39.7 & 2.4 & 30.6 & & & \\
\hline PFN 24-3 & 39.7 & 2.4 & 30.6 & & & \\
\hline$P F N$ 30-3 & 33.9 & 3.3 & 31.5 & & & \\
\hline$P F N$ 40-3 & 33.9 & 3.3 & 31.5 & & & \\
\hline PFN 50-3 & 37.6 & 3.1 & 31.1 & & & \\
\hline PFN 60-3 & 37.6 & 3.1 & 31.1 & & & \\
\hline
\end{tabular}

tests results of same lot of material;

$f_{c}$ is the highest compressed concrete stress;

$f_{c t}$ is the highest tensile concrete stress;

$f_{y}$ is the tensile yield steel strength;

$f_{u}$ is the ultimate tensile steel strength;

$E_{s}$ is the steel modulus of elasticity;

$E_{c}$ is the concrete modulus of elasticity.

\section{Numerical Model}

In order to simulate the columns behavior subjected to combine axial load and bending, a computing program was used, which was developed using Fortran compiler. The numerical model, called FLECO2C, simulates the same tests conditions, applying load in steps until failure. FLECO2C is divided in two parts: a nonlinear physical model, which considers the physical nonlinearities of concrete and reinforcement, and a nonlinear geometric model, which uses the results obtained on nonlinear physical model to calculate the horizontal displacements.

\subsection{Consideration of Physical Nonlinearity}

The consideration of physical nonlinearity of numerical model was presented by Nagato and Regis [9] and the program was called CACODI. The CACODI program was made using Fortran 77 compiler and the aim was the study of shear resistance of reinforced concrete elements under axial load and bending with different longitudinal reinforcement ratios.

The model is based on compression field theory by Vecchio and Collins [2], which developed a computing program that applies the theory called SMAL (shear and moment under axial load).

For the compressed concrete behavior, the stress-strain law proposed by Carreira and Chu [10] was adopted:

$$
\begin{gathered}
\sigma_{c}=\frac{f_{c} \beta\left(\varepsilon_{c} / \varepsilon_{0}\right)}{\beta-\left(\varepsilon_{c} / \varepsilon_{0}\right)^{\beta}} \\
\beta=\frac{1}{1-\frac{f_{c}}{E_{c} \varepsilon_{0}}}
\end{gathered}
$$

where, $\sigma_{c}$ is the compressed concrete stress; $f_{c}$ is the highest compressed concrete stress; $\beta$ is the material parameter; $\varepsilon_{c}$ is the compressed concrete strain; $\varepsilon_{0}$ is the strain corresponding to the highest compressed concrete strain; $E_{0}$ is the initial elasticity modulus of concrete.

The variable $C T$ (concrete type) was used in main program to choose the concrete behavior with descendent line or without descendent line (Fig. 4). This law is valid to $\varepsilon_{u} \leq \varepsilon_{c} \leq 0$ to concrete with descendent line $(C T=1)$, or $\varepsilon_{0} \leq \varepsilon_{c} \leq 0$ to concrete without descendent line $(C T=2)$, which $\sigma_{c}=f_{c}$, $\varepsilon_{u} \leq \varepsilon_{c} \leq 0$ (Fig. 4). All analyses were done using concrete with descendent line $(C T=1)$, and the concrete without descendent line was disposed for design purposes.

For the tensioned concrete behavior, a similar law 
used by Maia [11] was adopted, but the tension strength of concrete used was defined by Vecchio and Collins [2] (Fig. 5):

$$
\begin{gathered}
\sigma_{c t}=E_{0} \varepsilon_{t} \text { for } \varepsilon_{t} \leq \varepsilon_{c r} \\
\sigma_{c t}=f_{c r}\left(\frac{\varepsilon_{u t}-\varepsilon_{t}}{\varepsilon_{u t}-\varepsilon_{c r}}\right)^{2} \text { for } \varepsilon_{c r}<\varepsilon_{t} \leq \varepsilon_{u t} \\
\sigma_{c t}=0 \text { for } \varepsilon_{t} \geq \varepsilon_{u t} \\
f_{c r}=0.33 \sqrt{f_{c}}(\mathrm{MPa}) \\
\varepsilon_{c r}=f_{c r} / E_{0}
\end{gathered}
$$

where, $\sigma_{c t}$ is the tensile concrete stress; $f_{c r}$ is the cracking tensile concrete stress; $\varepsilon$ is the tensile concrete strain; $\varepsilon_{u t}$ is the highest tensile concrete strain; $\varepsilon_{c r}$ is the strain corresponding to the highest tensile concrete

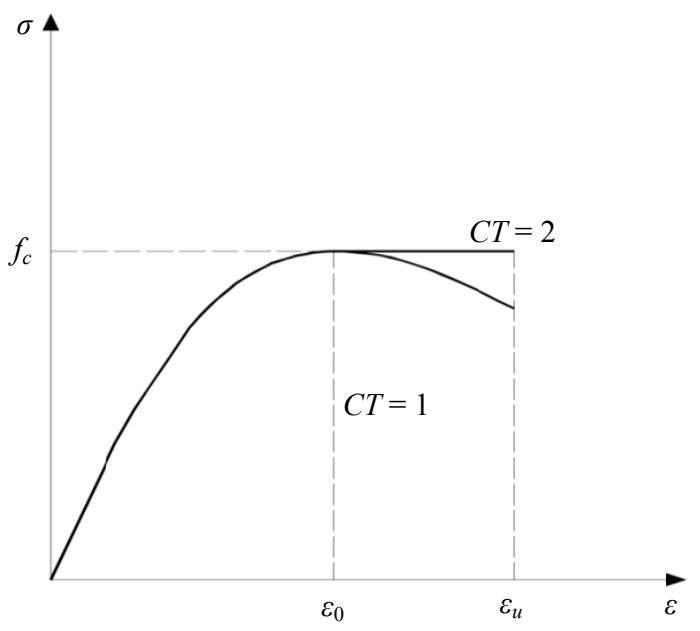

Fig. 4 Stress-strain diagram of compressed concrete.

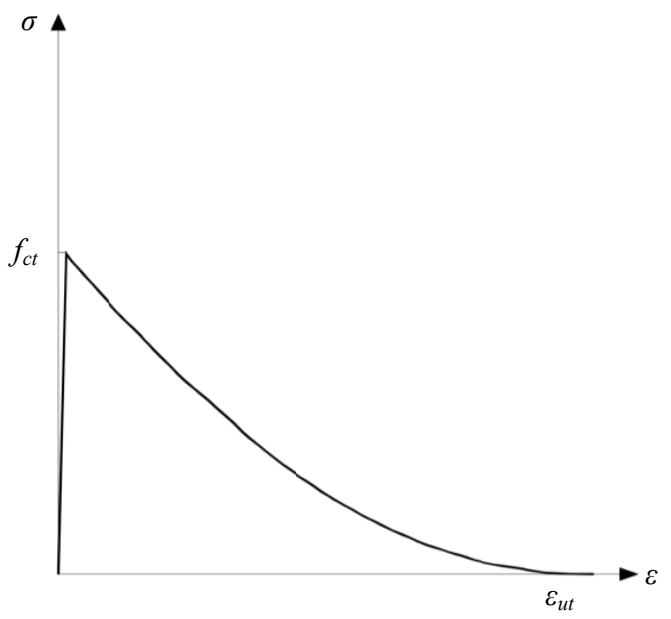

Fig. 5 Stress-strain diagram of tensile concrete. strain; $E_{0}$ is the initial elasticity modulus of concrete.

The highest tensile concrete strain $\varepsilon_{u t}=5 \times 10^{-3}$ on CACODI program was adopted because it leads to adjust results with experimental results presented by Vecchio [12].

A bilinear behavior was adopted to longitudinal steel bars (Fig. 6), assuming that stress-strain diagram is valid to compression and tension.

The reinforcement stress was obtained by:

$$
\begin{gathered}
\sigma_{s}=E_{s} \varepsilon_{s} \text { when } \varepsilon_{y}<\varepsilon_{s}<\varepsilon_{y} \\
\sigma_{s}= \pm f_{y} \text { when } \varepsilon_{y} \geq \varepsilon_{s} \geq \varepsilon_{y}
\end{gathered}
$$

where, $\sigma_{s}$ is the steel stress; $E_{s}$ is the steel modulus of elasticity; $\varepsilon_{s}$ is the steel strain; $f_{y}$ is the tensile yield steel strength; $\varepsilon_{y}$ is the is the yield tensile steel strain and $\varepsilon_{s u}$ is the highest tensile steel strain.

\subsection{Calculation Process}

The rectangular cross section, given by $b$ and $h$, was discretized in " $m$ " concrete layers and " $n$ " reinforced layers, where each concrete layer has width $b_{i}$, height $h_{i}$ and position in relation to the highest cross section compressed fiber $\left(y_{c i}\right)$, and each reinforced layer has the area of longitudinal steel $\left(A_{s l j}\right)$ and position in relation to the highest cross section compressed fiber $\left(y_{s l j}\right)$ (Fig. 7).

After changing the neutral axis deep and curvature, it was possible to determine in each concrete layer strain $\left(\varepsilon_{c l i}\right)$, stress $\left(\sigma_{c l i}\right)$, concrete load $\left(F_{c l i}\right)$, transversal loads

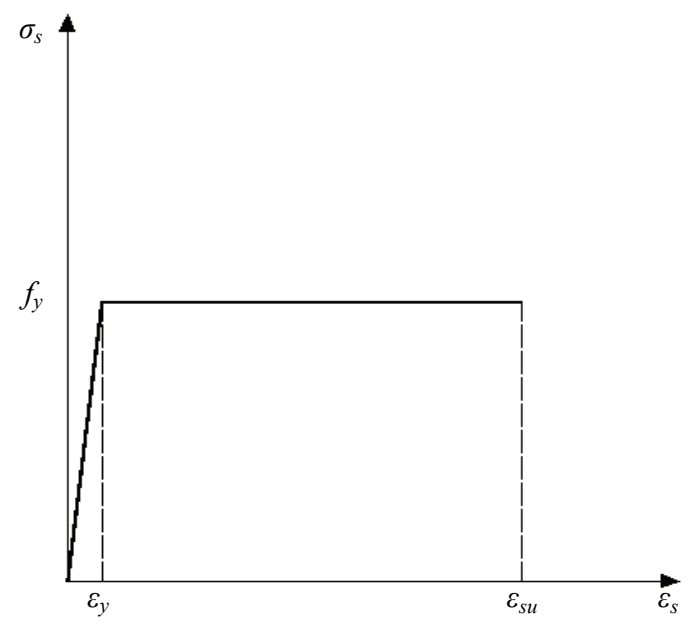

Fig. 6 Stress-strain diagram of longitudinal bars (CA-50). 

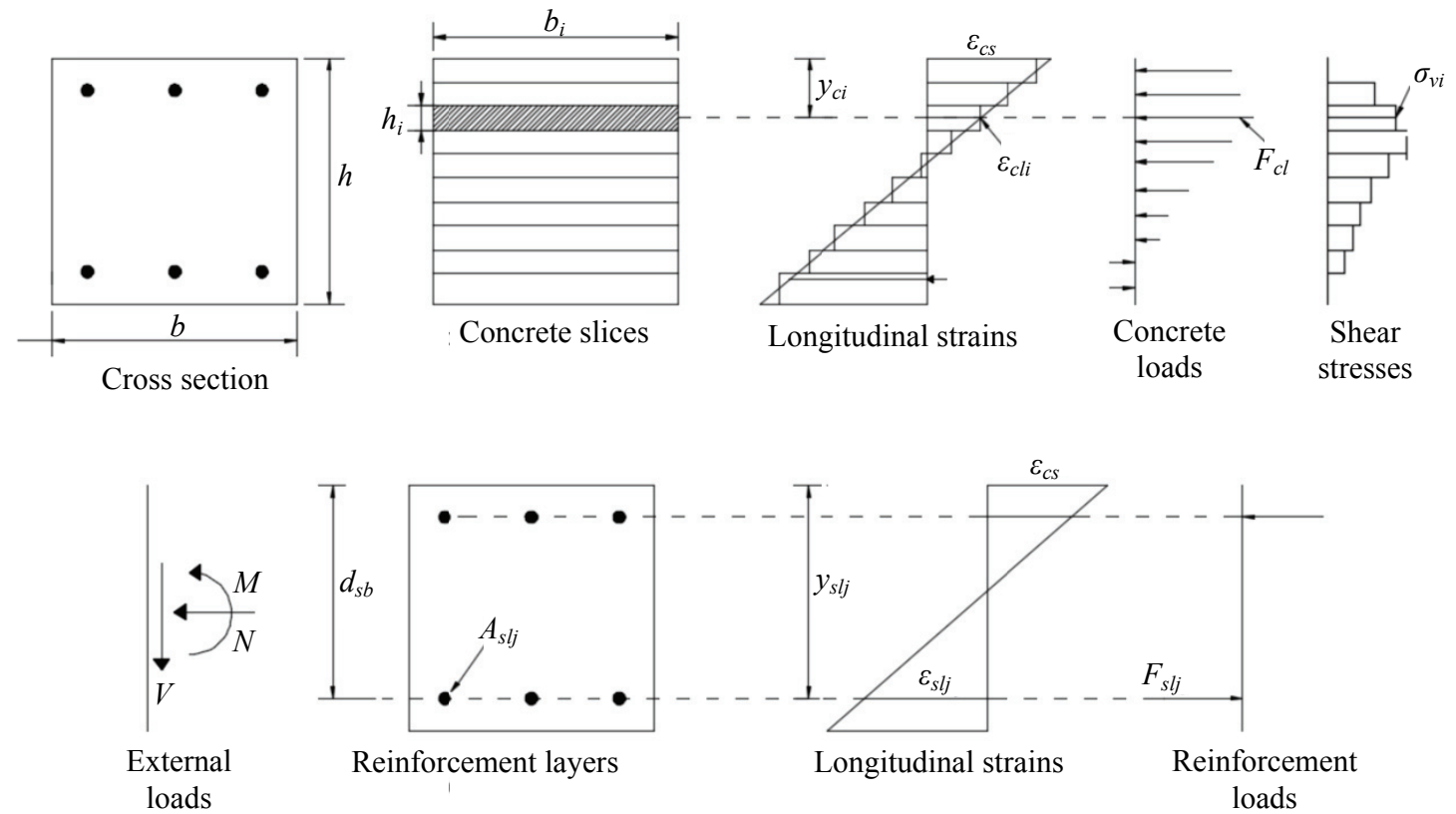

Fig. 7 Cross section discretization.

$\left(\sigma_{v i}\right)$ and in each reinforced layer strain $\left(\varepsilon_{s l j}\right)$, stress $\left(\sigma_{s l j}\right)$ and reinforced load $\left(F_{s l j}\right)$.

The following hypotheses were considered on CACODI program:

- Bernoulli hypothesis that means the plane sections remain plane until failure;

- equilibrium condition that means the internal forces balance external forces.

Given these hypotheses, it is possible to reach the cross section equilibrium by the following equations:

$$
\begin{gathered}
N=\sum_{i=1}^{m} \sigma_{c l} b_{i} h_{i}+\sum_{j=1}^{n} \sigma_{s l j} A_{s l j} \\
M=\sum_{i=1}^{m} \sigma_{c l i} b_{i} h_{i}\left(y_{c i}-h\right)+\sum_{j=1}^{n} \sigma_{s l i} A_{s i}\left(y_{s j}-h\right) \\
V=\sum_{i=1}^{m} \tau_{v i} b_{i} h_{i}
\end{gathered}
$$

where, $N$ is the axial force, $M$ is the bending moment and $V$ is the shear force.

The first summation of Eq. (10) determines the internal concrete resultant $(R C)$ and the second one determines the internal reinforcement resultant $(R S)$. In Eq. (11), the first and the second summations determine the internal bending moment related to internal concrete resultant $(M C)$ and related to internal reinforcement resultant (MS), respectively. In Eq. (12), the summation determines the internal concrete resultant by the compression field theory.

The curvature of the cross section is determined by neutral axis variation until equilibrium of internal forces is satisfied. The calculus is processed by iteration.

It is important to emphasize that it is possible to ignore the shear load in the program, and in this work, the shear load was ignored.

\subsection{Consideration of Geometric Nonlinearity}

The CACODI program analyses an isolated cross section under axial load, shear load and bending, and it does not apply directly to second order effects, which occur in columns under axial load and bending, yet these results can be used to do that analysis.

In order to determine the second order effects in a column under axial load and bending, a subroutine, called SECORDER, was developed, using the moment-area theorem.

Half of the column was divided in cross sections $(s)$, and in each load step the main program analyses each cross section $(s)$ subjected to axial load $(N)$ and 
bending $(M)$, given by the following Eq. (13):

$$
M_{s}=N \cdot\left(e+\delta_{(i-1, s)}\right)
$$

where, $e$ is the initial eccentricity, $\delta_{(i-1, s)}$ is the column horizontal displacement of section $(s)$ determined on the previous iteration $(i-1)$.

The main program determines the curvature for each section $(P H I)$ and the SECORDER subroutine converts these curvatures into displacements, using the moment-area theorem (Fig. 8). The new displacements are used to calculate the new bending moments, which are introduced in the main program again until they reach an established tolerance given by the user.

\section{Comparison of Test Data with Numerical Model Results}

On this topic, the results obtained on tests are compared with FLECO2C estimates. Initially, concrete strain and horizontal displacements at mid-height of columns are presented, during load steps until failure and finally the ultimate loads of columns.

\subsection{Concrete Strains}

Concrete average strains at a more compressed surface located at mid-height of columns during the load steps until failure are presented and compared with numerical program results (Fig. 9).

It can be noticed that the concrete strains predicted by the numerical model presents close results of concrete strains for nearly all cases. The seen-far behaviors were given by $P F N$ 12-3, PFN 18-3 and $P F N$ 24-3 columns, probably due to high geometric imperfections or due to incorrect load eccentricity.

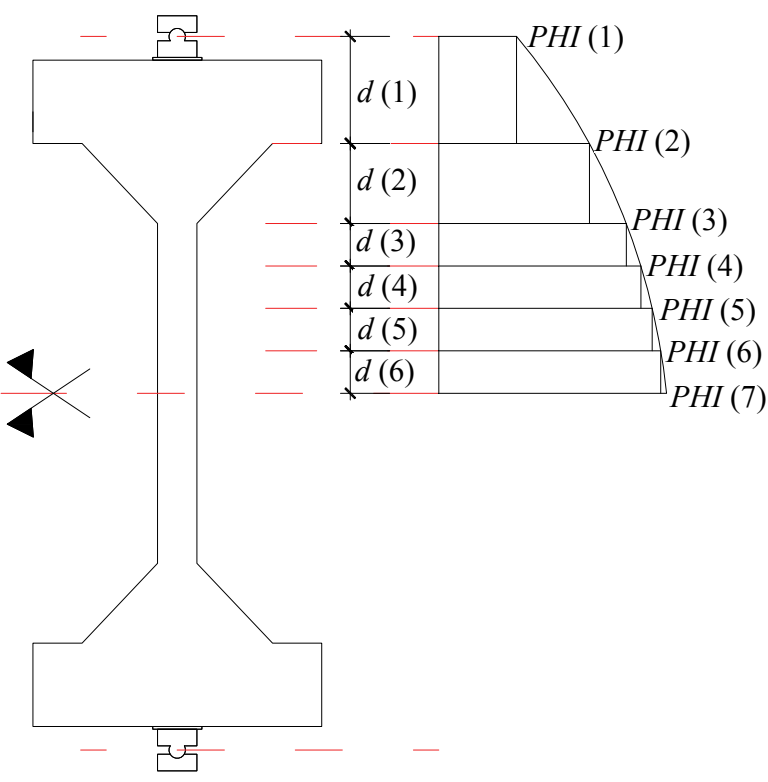

Fig. 8 Column discretization.

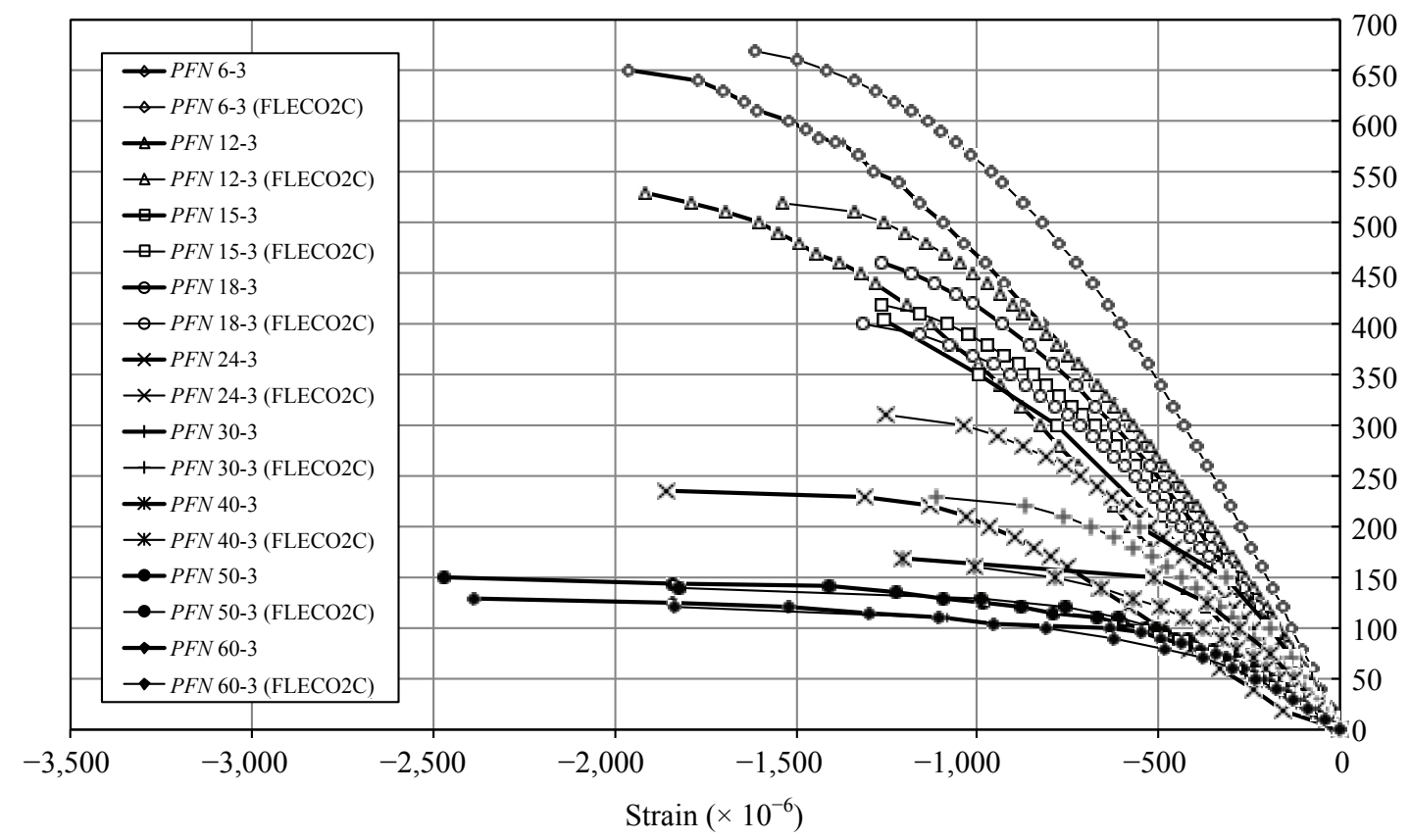

Fig. 9 Concrete strains at mid-height. 


\subsection{Horizontal Displacements}

Horizontal displacements at mid-height of columns during the load steps until failure are presented and compared with numerical model results (Fig. 10).

It can be seen that the horizontal displacements predicted by the numerical model presents close results of horizontal displacements for almost all cases. Column PFN 24-3 presented far results, probably due to high geometric imperfections or due to incorrect load eccentricity. It was necessary to retest $P F N$ 24-3 column to validate the results.

\subsection{Ultimate Loads}

With FLECO2C, it was possible to estimate the ultimate load of each column. The horizontal displacements were incremented in each load step until the column failure.

The ultimate load was determined when it was not possible to balance the external load with the cross section internal load. Table 3 shows a comparison between numerical loads and ultimate loads with statistic results, and Fig. 11 shows $F_{u} / F_{\text {num }}$ plotted against relative eccentricity $e / h$.

As shown in Table 3 and Fig. 11, the ultimate loads predicted by the numerical model presents close results for nearly all cases, except for PFN 18-3, PFN 24-3 and PFN 30-3.

\section{Analysis of Numerical Results}

On this topic, an analysis is presented between results obtained on a numerical model and obtained on tests. The whole analysis was done using applied load eccentricity, considered at cross section center of gravity, and geometric imperfections were not considered.

An accurate concrete strain estimate and horizontal displacements on PFN 6-3 column results can be seen in Figs. 9 and 10, when compared with FLECO2C results. The displacement curve estimated by FLECO2C presented an adequate approximation when compared with test results, presenting greater stiffness and ultimate load $4 \%$ greater than the test result. Probably, the real eccentricity of column was greater than the one used on the numerical model.

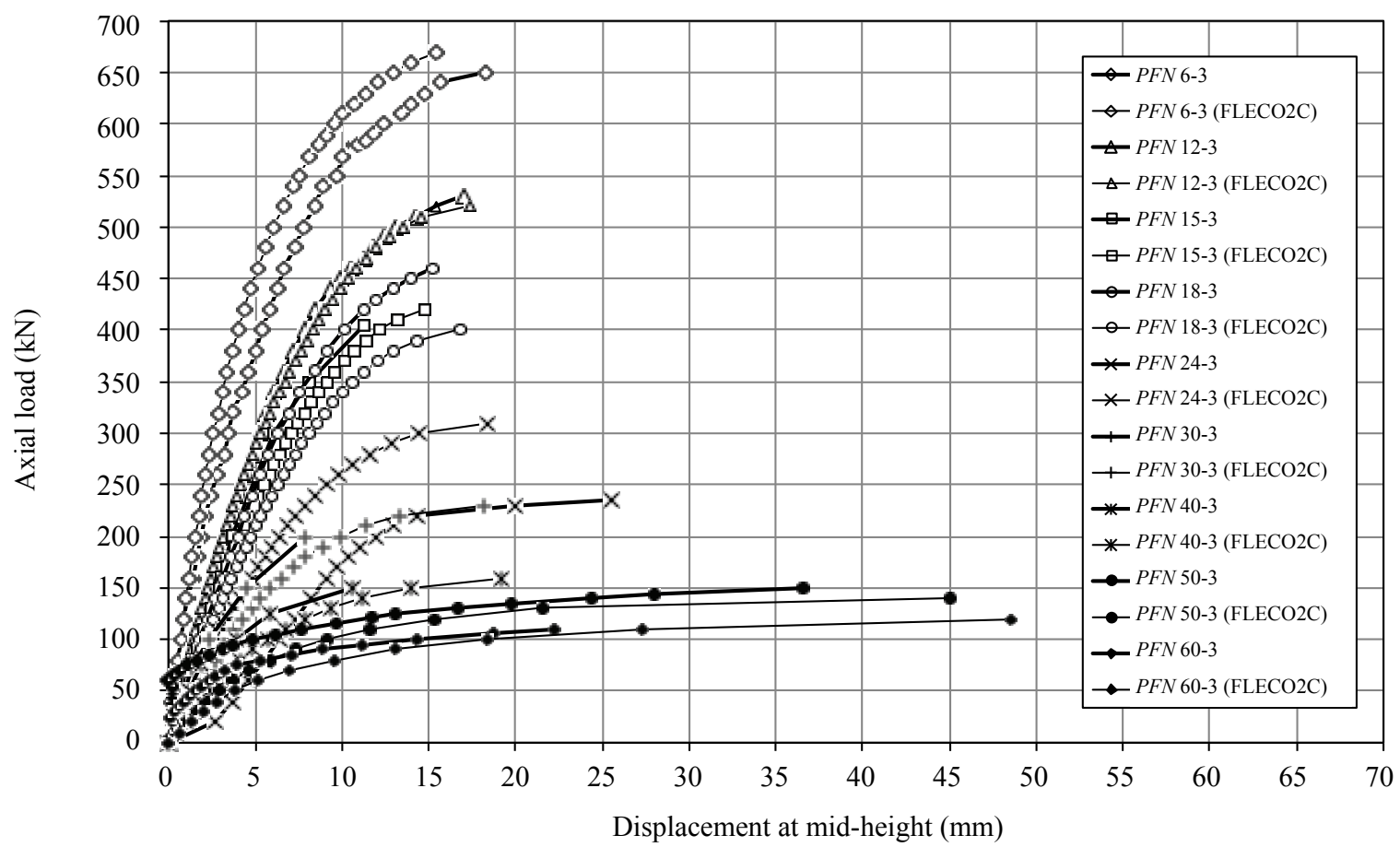

Fig. 10 Horizontal displacements at mid-height. 
Table 3 Ultimate loads versus numerical loads.

\begin{tabular}{lrlllll}
\hline Column & $F_{u}(\mathrm{kN})$ & $F_{\text {num }}(\mathrm{kN})$ & $F_{u} / F_{\text {num }}$ & Mean & Standard deviation & Coefficient of variation $(\%)$ \\
\hline PFN 0-3 & $1,053.0$ & 980.0 & 1.07 & & & \\
PFN 6-3 & 652.0 & 680.0 & 0.96 & & & \\
$P F N ~ 12-3$ & 535.0 & 530.0 & 1.01 & & & \\
$P F N ~ 15-3$ & 446.5 & 430.0 & 1.04 & & & \\
$P F N ~ 18-3$ & 460.5 & 410.0 & 1.12 & 1.01 & 0.10 & \\
$P F N ~ 24-3$ & 241.0 & 320.0 & 0.75 & & & \\
$P F N ~ 30-3$ & 254.8 & 230.0 & 1.11 & & & \\
$P F N ~ 40-3$ & 170.2 & 170.0 & 1.00 & & & \\
$P F N ~ 50-3$ & 155.0 & 150.0 & 1.03 & & & \\
$P F N ~ 60-3$ & 131.0 & 130.0 & 1.01 & & & \\
\hline
\end{tabular}

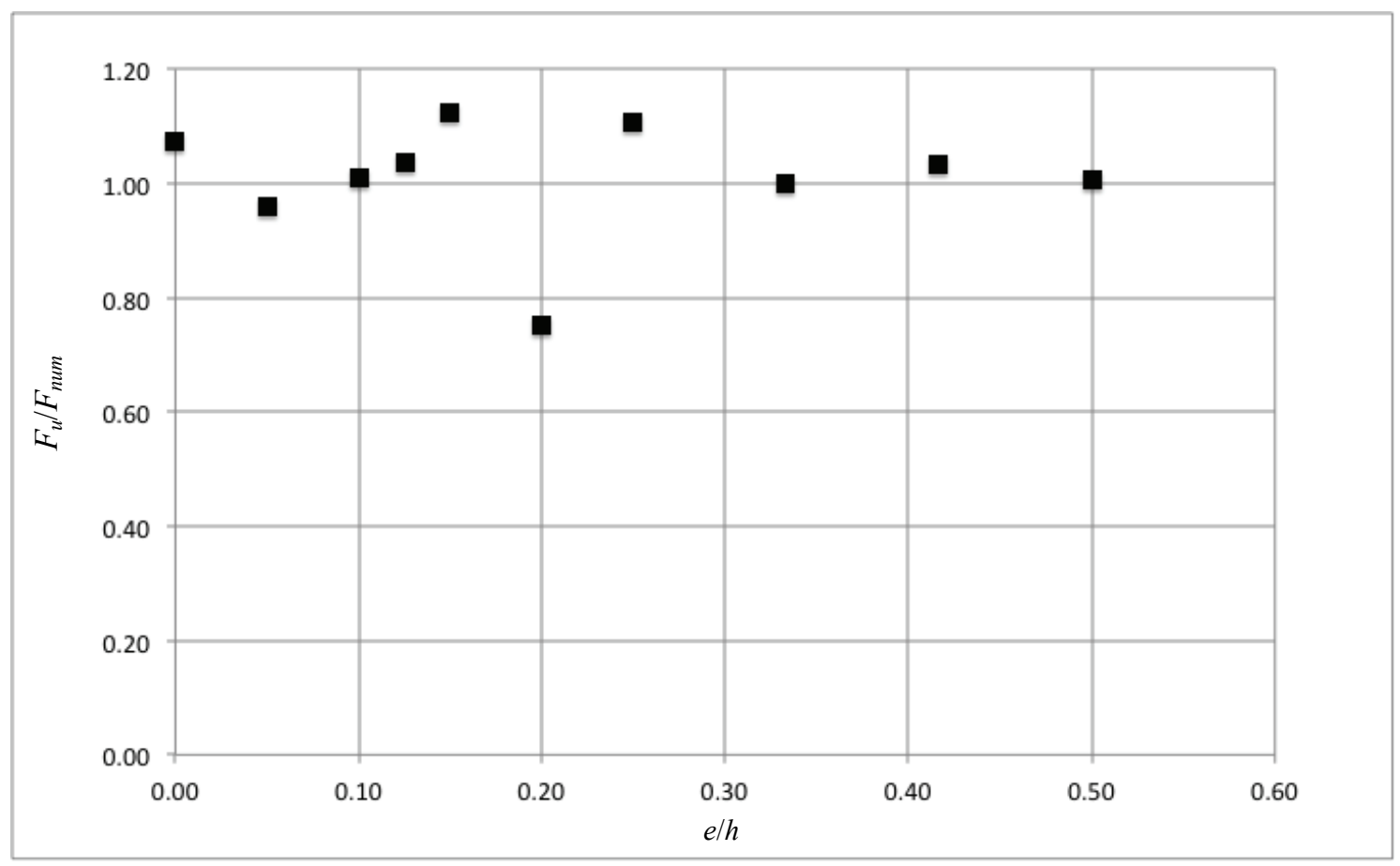

Fig. $11 F_{u} / F_{\text {num }}$ plotted against relative eccentricity $e / h$.

It is possible to see a fragile behavior of columns with eccentricity less or equal to $18 \mathrm{~mm}$, given by PFN 6-3, PFN 12-3, PFN 15-3 and PFN 18-3. All the others presented an asymptotic tendency of curve and were more frequently verified in columns with high eccentricity, on PFN 50-3 and PFN 60-3, as expected and obtained on numerical results.

The PFN 12-3 column presented a close behavior of horizontal displacements and ultimate load prediction, as can be seen in Fig. 10 and Table 3, respectively. The concrete strain obtained on the numerical model presented far results from the test of PFN 12-3 column, probably due to problems on strain gauges, as can be seen in Fig. 9.

The PFN 15-3 column presented adequate predicted results of concrete strain and horizontal behavior, in comparison with test results, as can be seen in Figs. 9 and 10. Better results could be given reducing the load step on test.

Figs. 9 and 10 point out far results of horizontal displacements and concrete strains on PFN 18-3 and PFN 24-3 column compared to FLECO2C results. The displacement curve estimated by FLECO2C presented lower stiffness on $P F N$ 18-3 results and higher stiffness on $P F N$ 24-3 results. Results of ultimate loads given by the numerical model presented $12 \%$ less than PFN 18-3 
ultimate load and 15\% greater than PFN 24-3 ultimate load. Probably, the real eccentricity of column was different than the one used on the numerical model or geometric imperfections affected those results. It is necessary to retest PFN 24-3 column to best validate the results.

Numerical results from $P F N$ 30-3, $P F N$ 40-3, $P F N$ 50-3 and PFN 60-3 presented close concrete strain results and horizontal displacements when compared with test results, as can be seen in Figs. 9 and 10 , evidencing a preponderance of bending moments on columns and presenting an asymptotic curve with tendency of instability of columns. Ultimate loads were very close with numerical loads predictions, except for $P F N$ 30-3 that presented ultimate load, given by the numerical model, $11 \%$ less than the test result.

\section{Conclusions}

The aim of this work was the development for a numerical study of reinforced concrete columns subjected to axial load and bending. The following conclusions are presented and about 10 columns are tested.

The FLECO2C program presented adequate results of ultimate loads, concrete strains and horizontal displacements in comparison with test results, presenting coherent results and close to the test results with a few exceptions.

All columns presented ratios of $F_{u} / F_{\text {num }}$ close to 1.00 , with exception to $P F N$ 18-3, PFN 24-3 and PFN 30-3, which probably had problems on geometric of columns or load eccentricity.

The best results were achieved in columns with relative eccentricity $e / h$ higher or equal to 0.25 ( $e \geq 30 \mathrm{~mm}$ ), evidencing difficulties in applying eccentricities lower than $30 \mathrm{~mm}$.

It is noteworthy that, at ultimate load, it is hard to obtain horizontal displacements and concrete strains because, at this moment, in some cases, the values increase indefinitely. Therefore, the test behavior is valid at close of ultimate load, mainly for columns with high eccentricity.

Factors, such as bonding of strain gauges, geometric imperfections of cross sections, test setup and handling of columns, may have affected some results.

\section{Acknowledgments}

The authors are grateful to Structures Laboratory of University of Brasilia and to the CNPq (National Council for Science and Technological Development) as Brazilian research development agencies.

\section{References}

[1] Nagato, Y. 1987. "Strength of Reinforced Concrete Members with Circular Cross-Section under the Combined Action of Shear, Axial, Compression and Bending Moment." Ph.D. thesis, Federal University of Rio de Janeiro, Rio de Janeiro.

[2] Vecchio, F. J., and Collins, M. P. 1982. "The Response of Reinforced Concrete to In-plane Shear and Normal Stresses." Publication No. 82-03, University of Toronto, Canada.

[3] Dantas, A. B. 2006. "Reinforced Concrete Columns Tested under Axial Load and Bending." Master thesis, University of Brasília. (in Portuguese)

[4] Santos, G. S. 2009. "Numerical and Experimental Analysis of Reinforced Concrete Columns Subjected to Axial Load and Bending." Master thesis, University of Brasília. (in Portuguese)

[5] Araújo, L. M. B. 2004. "Theoretical and Experimental Analysis of Reinforced Concrete Columns Subjected to Axial Load and Bending." Master thesis, Civil Engineering School, Federal University of Goiás. (in Portuguese)

[6] Adorno, A. L. C. 2004. "Theoretical and Experimental Analysis of Unreinforced and Reinforced Columns Subjected to Axial Load and Bending." Ph.D. thesis, University of Brasília. (in Portuguese)

[7] Melo, C. E. L. 2009. "Experimental and Numerical Analysis of Pin-Ended Reinforced Concrete Columns Subjected to Axial Load and Bending." Ph.D. thesis, University of Brasilia, 2009.

[8] Comite Euro-International du Beton. 1993. CEB-FIP Model Code 1990-Design Code. London: Comite Euro-International du Beton, 1993.

[9] Nagato, Y., and Regis, P. A. 1997. "Shear in Reinforced Concrete Members of Circular Sections: CACODI E SACCOL Programs." In Proceedings of XVIII CILAMCE-Ibero-Latin American Congress on Computational Methods in Engineering, 569-76. (in 


\section{Accordance with a Nonlinear Numerical Model}

Portuguese)

[10] Carreira, D. J., and Chu, K. H. 1985. "Stress-Strain Relationship for Plain Concrete in Compression." Journal of the American Concrete Institute 82: 797-804.

[11] Maia, A. C. F. 1979. "Nonlinear Analysis of Reinforced and Prestressed Concrete Frames in View of the Rheological Behavior of Concrete." Ph.D. thesis, University Pierre et Marie Currie.

[12] Vecchio, F. 1981. "Response of Reinforced Concrete Subjected to In-plane Shear and Normal Stresses." Ph.D. thesis, Universityof Toronto. 